\title{
BETWEEN AND WITHIN FIELD VARIABILITY OF NEW ZEALAND INDIGENOUS FLOWER VISITORS TO ONIONS
}

\author{
B.G. HOWLETT ${ }^{1}$, B.J. DONOVAN ${ }^{2}$, J.A. McCALLUM ${ }^{1}$, \\ L.E. NEWSTROM ${ }^{3}$ and D.A.J. TEULON ${ }^{1}$ \\ ${ }^{1}$ Crop \& Food Research, Private Bag 4704, Christchurch, New Zealand \\ ${ }^{2}$ Donovan Scientific Insect Research, Private Bag 4704, Christchurch, \\ New Zealand \\ ${ }^{3}$ Landcare Research New Zealand Ltd, PO Box 69, Lincoln, New Zealand \\ Corresponding author: howlettb@crop.cri.nz
}

\begin{abstract}
In New Zealand, few studies have documented the occurrence of indigenous flower visitors within crops. A five-year survey is examining the distribution, diversity and abundance of flower visitors in onion (Allium сера) fields located throughout New Zealand. Day-time observations from the first year of the survey recorded nine arthropod orders visiting onion flowers in the South Island, with Diptera (flies) and Hymenoptera being the most abundant. Over six fields the proportion of bees that were indigenous species (Apoidea) ranged from $<1 \%$ to $63.6 \%$. Common bee genera and fly families varied considerably in their presence and abundance, even over $17 \mathrm{~km}$. Moreover, counts of Lasioglossum spp. at five points within one field ranged from 0 to 576, demonstrating that the distribution of some flower visitors can be highly variable. Understanding crop flower visitors may help develop systems to reduce transgene flow should genetically modified crops be commercially produced in New Zealand.

Keywords: transgene flow, pollinators, New Zealand, onion, flower visitors.
\end{abstract}

\section{INTRODUCTION}

Pollen movement from genetically modified (GM) crops may lead to transgene escape through hybrid seed formation with weedy relatives (Halfhill et al. 2004) and non GM crops (Ramsay et al. 2003). To evaluate the likelihood of transgene flow, an understanding of the mechanisms that result in gene movement is essential. For arthropod pollinated crops, flower visitors may offer a path for transgene flow. Assessing the risk of transgene escape from these crops may be complicated by the large diversity of flower visitors in crops such as onion (Caron et al. 1975) and brassica (Abrol \& Kapil 1996). Moreover, the distances that pollen can be carried will depend on the behaviour of the different pollinating species and might be highly variable.

Honey bees (Apis mellifera) can travel several kilometres from their nest sites (Buchmann \& Shipman 1991) and bumblebees (Bombus spp.) have been observed $15 \mathrm{~km}$ from their nearest possible nest site (Mikkola 1984). The moth Helicoverpa armigera, an onion flower visitor in India (Kumar et al. 1985), may migrate $1000 \mathrm{~km}$ under certain conditions (Feng et al. 2004).

For insect-pollinated crops, detailed studies are required to quantify the diversity, distribution and abundance of flower-visiting indigenous arthropods and their ability to effectively pollinate plants over distance. In addition, an analysis of key factors that influence pollinator diversity, such as climate, site-specific characteristics, geographic location and how these factors might influence seasonal and yearly fluctuations of pollinators, is necessary. Allium cepa (onion) is being used as a model crop to examine these factors. To date, the presence and abundance of indigenous species visiting and 
pollinating onion flowers have not been well studied in New Zealand although the introduced honey bee is specifically placed in onion seed fields to increase pollination efficiency (Crane \& Walker 1984). A survey is thus being conducted to assess the flower visitors to onion fields at multiple sites and locations. The survey will be conducted over 5 consecutive years to assess temporal and spatial variation in pollinator assemblages in the North and South Islands of New Zealand. Observation data collected from the South Island in the first year of the study are examined in this paper.

\section{METHODS}

The study sites consisted of commercially grown onion seed crops located in three regions, Marlborough, Canterbury and Central Otago, of the South Island of New Zealand (Fig. 1). There were two fields in each region, giving a total of six crops studied. Observations were conducted throughout January 2004 when fields were at peak flowering to document the type and number of arthropod flower visitors. The observations were conducted on days with light or no wind (less than $20 \mathrm{~km} / \mathrm{h}$ ) and with full or partial sunshine. No rainfall occurred on any of the observation days. Arthropods were identified to at least Order level and, where possible, to species. Fields examined were rectangular and between 0.75 and 2.0 ha.

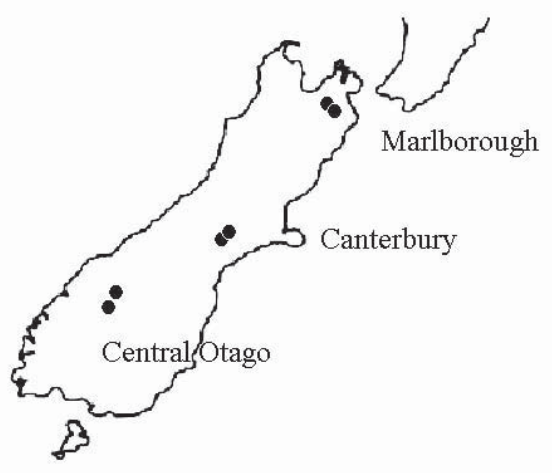

\section{FIGURE 1: The location of South Island onion fields used to conduct observations.}

Within each field, observations were conducted at five sample points - just inside each corner and in the centre. At each sample point, 150 flowering onion umbels (75 male and 75 female) were observed within a $5 \mathrm{~m}$ radius of a marked centre point. Umbels that were not flowering or had fewer than 30 open flowers (visually estimated) were not included in the study. Umbels were examined along rows within the confines of the marked sample point. Each umbel was initially observed at a distance of approximately $1 \mathrm{~m}$ and all arthropods visiting flowers were noted. A closer inspection of the umbel was then made at a distance of approximately $10 \mathrm{~cm}$ to record smaller arthropods. Two observers were used to conduct observations, but only one observer was required per field. Observers were initially trained to ensure standardised observation techniques and accurate identification of flower visitors. All but one field (Canty 1 in Table 1) were observed by the same observer.

Approximately 10 minutes were required to complete the observations at each sample point and 60 minutes to complete observations across an entire field. Each field was examined eight times throughout the day at 2-hour intervals with the first set of observations starting at 6 am and the final at $8 \mathrm{pm}$. An overall count for each within-field 
sample point was calculated for each observed arthropod taxon by summing the eight observation periods. An overall field tally was then determined by summing the five field sample points. The data presented utilise the counts from six fields (two in each district) to demonstrate the range of flower visitors observed, while counts of fly families and bee genera and species are used to demonstrate the variability between selected fields. Finally, the data for one bee genus (Lasioglossum) are used to demonstrate the variability in flower visitor numbers across sample points in a single field.

The term macro (i.e. macro-diptera and macro-arthropod) was used to define larger arthopods and refers to species that have a body length greater than $5 \mathrm{~mm}$. The body length included head, thorax and abdomen but excluded appendages such as antennae, stylets, wings, legs and ovipositors.

\section{Flower visitors within onion fields}

\section{RESULTS}

Indigenous arthropods were common onion flower visitors, with Hymenoptera (bees in particular) and flies being the most abundant. Other orders that were observed in contact with flowers were Coleoptera, Lepidoptera, Heteroptera, Thysanoptera, Neuroptera, Odonata and Araneida.

Bees were the most numerous onion flower visitors across the observed fields. The introduced honey bee and bumble bees were observed in all six fields (two in each district), while indigenous bees from the genera Lasioglossum were present in four fields and Leioproctus in three fields.

Flies were also common flower visitors, although, macro-diptera were less numerous than bees in all fields observed. In one Canterbury field there were 113 macro-diptera individuals representing 39.6\% of all macro-arthropod visitors (285 in total).

\section{Variability of flower visitors between fields}

The proportion of indigenous arthropods observed between the six fields could be highly variable. For example, the majority of the bees observed in the second Marlborough field were indigenous species while in the second Canterbury field, their proportion was less than $1 \%$ (Table 1 ).

TABLE 1: Percentage of introduced versus indigenous bees in six onions fields located throughout the South Island of New Zealand.

\begin{tabular}{lcccccc}
\hline & $\begin{array}{c}\text { Central } \\
\text { Otago 1 }\end{array}$ & $\begin{array}{c}\text { Central } \\
\text { Otago 2 }\end{array}$ & Canty 1 & Canty 2 & Marlb 1 & Marlb 2 \\
\hline Introduced bees & 93.0 & 58.3 & 40.3 & 99.4 & 79.1 & 36.4 \\
Indigenous bees & 7.0 & 41.7 & 59.7 & 0.6 & 20.9 & 63.6 \\
\hline
\end{tabular}

Likewise, the number of some common flower visitors was highly variable between fields. A comparison between the six fields showed that not all bee genera (indigenous and introduced) or fly families (only indigenous species counted) were present across fields. In addition, counts could differ by 100 fold for some taxa (Table 2). Of particular note was the difference between the two Central Otago fields with indigenous species from the families Calliphoridae, Syrphidae and Tachinidae being observed in larger numbers in field 1, while Leioproctus spp. were much more commonly observed in field 2 (Table 2). These fields were spatially separated by only $17 \mathrm{~km}$.

\section{Variability of flower visitors within a field}

The abundance of specific arthropod taxa can be highly variable within a single onion field. At one field in the Marlborough district, sample point data for indigenous bees from the genus Lasioglossum varied greatly (Fig. 2). In this field, 576 individuals were observed visiting onion flowers at the north-east sample point while at the other sample points, numbers were much lower. For the centre and south-west sample points no Lasioglossum were observed (Fig. 2). 
TABLE 2: Number of individuals of specified bee genera and fly families observed visiting onion flowers within six fields located throughout the South Island of New Zealand.

\begin{tabular}{|c|c|c|c|c|c|c|}
\hline Arthropod taxa & $\begin{array}{l}\text { Central } \\
\text { Otago } 1 \\
\end{array}$ & $\begin{array}{l}\text { Central } \\
\text { Otago } 2 \\
\end{array}$ & Canty 1 & Canty 2 & Marlb 1 & Marlb 2 \\
\hline \multicolumn{7}{|l|}{ Bees } \\
\hline Apis mellifera & 989 & 383 & 93 & 157 & 1157 & 330 \\
\hline Bombus spp. & 9 & 3 & 17 & 4 & 9 & 8 \\
\hline Leioproctus spp. ${ }^{1}$ & 22 & 276 & 0 & 0 & 3 & 0 \\
\hline Lasioglossum spp. ${ }^{1}$ & 53 & 0 & 148 & 1 & 305 & 590 \\
\hline \multicolumn{7}{|l|}{ Flies } \\
\hline Calliphoridae $^{1}$ & 28 & 0 & 0 & 21 & 15 & 2 \\
\hline Syrphidae $^{1}$ & 33 & 5 & 4 & 13 & 16 & 4 \\
\hline Tachinidae $^{1}$ & 22 & 4 & 2 & 0 & 3 & 3 \\
\hline
\end{tabular}

${ }^{1}$ Only indigenous species counted.

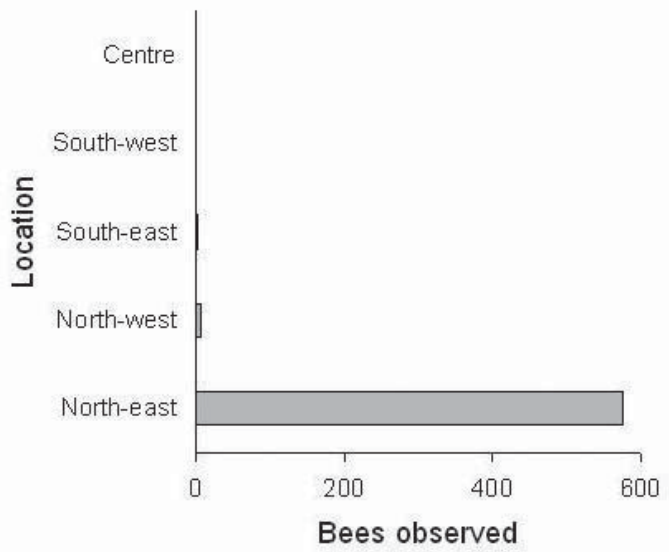

FIGURE 2: The total number of bees from the genus Lasioglossum observed visiting onion flowers at five sample points within a field located in the Marlborough district, South Island, New Zealand. All are indigenous Lasioglossum spp.

\section{DISCUSSION}

The assemblages of arthropods visiting flowers in onion crops grown in the South Island of New Zealand were complex and variable. Arthropods from several orders including many indigenous species were found visiting flowers. Of these, bees and flies (both native and introduced) were the most commonly observed. However, their distribution between fields can be highly variable. The data also suggest that the distribution of specific flower visitors such as Lasioglossum spp. can vary greatly within a field. The data presented in this study are preliminary, and a full statistical analysis across all sites is required to determine the full extent of the diversity and variability of onion flower visitors. 
Observation data are inherently biased towards insects that are visually obvious to the human eye and ideally, such data should be supplemented with those produced by additional sampling methods, such as water traps (Howlett et al. 2005). Moreover, only daytime visitors have so far been examined. To address these shortcomings, water traps are being used as an additional method to collect arthropods in flowering onion and brassica crops. The traps collect arthropods both night and day over a period of several days. These data will provide additional information about the abundance of flower visitors and will help address the biases implicated in the use of a single method.

The arthropod taxa observed on onion flowers in this study are similar to others reported from India (Kumar et al. 1985), North America (Caron et al. 1975), South America (Lorenzon \& Martinho 1992; Witter \& Blochtein 2003), Europe (Benedek \& Gaal 1972) and Africa (Green 1973), with fly and bees frequently listed as the most abundant taxa by these authors. Caron et al. (1975) compared onion pollinators collected from New York State with data collected by Bohart et al. (1970, cited by Caron et al. 1975) in Utah and found variation in the type and importance of each pollinating species. The present study demonstrates that the abundance and distribution of various indigenous fly families and bee genera can vary greatly across fields separated by much shorter distances (e.g. $17 \mathrm{~km}$ ), and in some cases, even within fields.

Of the indigenous arthropods observed visiting onion flowers, the dominance of bee and fly individuals is not surprising given that these taxa are also regarded as important insect pollinators of native flora (Godley 1979; Primack 1983; Newstrom \& Robertson 2005). In addition, Macfarlane \& Ferguson (1983) list these taxa as the most commonly observed indigenous arthropods visiting the flowers of the exotic kiwifruit.

To develop an understanding of how transgene flow might occur for crops in New Zealand, it is essential that the extent to which indigenous pollinators visit crops and vary across locations is determined. This project has demonstrated that indigenous assemblages of visitors to onion crop flowers are both diverse and variable. Future work will aim at assessing how these assemblages change across years, the ability of key flowers visitors to pollinate and the distances over which they might move pollen. Key climatic and phenological variables and site-specific characteristics (such as soil type and microclimate) that might influence the abundance and activity of pollinators will also be examined. The long-term data collected from this project will allow for the development of (a) methods for rapidly and efficiently monitoring populations of pollinating species in New Zealand crop plants, (b) a database of flower visitors that are likely pollinators of a range of crop and native plants and (c) systems to reduce transgene flow.

\section{ACKNOWLEDGEMENTS}

This project is being funded through the New Zealand Foundation for Research, Science and Technology. We thank Bede McCarthy, Melanie Walker and Kristin Stokes for providing technical assistance and Tracy Williams for editorial assistance. South Pacific Seeds New Zealand Ltd and Seminis Vegetable Seeds, NZ (Ltd) provided access to onion fields and crop information.

\section{REFERENCES}

Abrol DP, Kapil RP 1996. Studies on abundance and importance of insect pollinators for oilseed production. Journal of Insect Science 9: 172-174.

Benedek P, Gaal E 1972. The effect of insect pollination on seed onion, with observations on the behaviour of honeybees on the crop. Journal of Apicultural Research 11: $175-180$.

Bohart GE, Nye WP, Hawthorn LE 1970. Onion pollination is affected by different levels of pollinator activity. Utah State University Agricultural Experiment Station Bulletin: 483.

Buchmann SL, Shipman CW 1991. Foraging distances flown by honey bee colonies: analyses using Mathematica software. American Bee Journal 131: 771. 
Caron DM, Lederhouse RC, Morse RA 1975. Insect pollinators of onion in New York State. Hortscience 10: 273-274.

Crane E, Walker P 1984. Pollination directory for world crops. International Bee Research Association, London.183 p.

Feng HQ, Wu KM, Cheng DF, Guo YY 2004. Northward migration of Helicoverpa armigera (Lepidoptera : Noctuidae) and other moths in early summer observed with radar in northern China. Journal of Economic Entomology 97: 1874-1883.

Godley EJ 1979. Flower biology in New Zealand. New Zealand Journal of Botany 17: 441-66.

Green JH 1973. Notes on the use of flies for onion pollination under arid conditions in Nigeria. Tropical Agriculture 50: 165-167.

Halfhill MD, Zhu B, Warwick SI, Raymer PL, Millwood RJ, Weissinger AK, Stewart CN Jr. 2004. Hybridization and backcrossing between transgenic oilseed rape and two related weed species under field conditions. Environmental Biosafety Research 3: 73-81.

Howlett BG, Kitching RL, Boulter SL 2005. Interception traps in canopy inflorescences: targeting a neglected fauna. International Journal of Tropical Insect Science 25: in press.

Kumar J, Mishra RC, Gupta JK 1985. The effect of mode of pollination on Allium species with observation on insects as pollinators. Journal of Apicultural Research 24: 62-66.

Lorenzon MCA, Martinho MR 1992. Pollinators of flowering onions in Igarape, Minas Gerais State. Anais da Sociedade Entomologica do Brasil 21: 383-389.

Macfarlane RP, Ferguson AM 1983. Kiwifruit pollination: a survey of the insect pollinators in New Zealand. V Symposium International sur la Pollination. Pp. 367-373.

Mikkola K 1984. Migration of wasp and bumble bee queens across the Gulf of Finland (Hymenoptera: Vespidae and Apidae). Notulae Entomologicae 64: 125-128.

Newstrom LE, Robertson A 2005. Progress in understanding pollination systems in New Zealand. New Zealand Journal of Botany 43: in press.

Primack RB 1983. Insect pollination in New Zealand mountain flora. New Zealand Journal of Botany 21: 317-333.

Ramsay G, Thompson C, Squire G 2003. Quantifying landscape-scale gene flow in oilseed rape. Department for Environment, Food \& Rural Affairs, Dundee. http:www.defra. gov.uk/environment/gm/reseach/epg-rg0216.htm [accessed 13 September 2004].

Witter S, Blochtein B 2003. Effect of pollination by bees and other insects on the production of onion seeds. Pesquisa Agropecuaria Brasileira 38: 1399-1407. 